\title{
Glucose-dependent, cAMP-mediated ATP efflux from Saccharomyces cerevisiae
}

\author{
Rodney Boyum and Guido Guidotti
}

Department of Molecular and Cellular Biology, Harvard University, 7 Divinity Ave, Cambridge, MA 02138, USA
Author for correspondence: Rodney Boyum. Tel: +1617 4952301. Fax: + 16174958308.
e-mail: Boyum@fas.harvard.edu

\begin{abstract}
Extracellular ATP plays an important role in the physiology of multicellular organisms; however, it is unknown whether unicellular organisms such as yeast also release ATP extracellularly. Experiments are described here which show that Saccharomyces cerevisiae releases ATP to the extracellular fluid. This efflux required glucose and the rate was increased dramatically by the proton ionophores nigericin, monensin, carbonyl cyanide $\boldsymbol{m}$ chlorophenylhydrazone and carbonyl cyanide p-(trifluoromethoxy)phenylhydrazone; ATP efflux was also increased by the plasma membrane proton pump inhibitor diethylstilbestrol. The increase in the concentration of extracellular ATP was not due to cell lysis or general disruption of plasma membrane integrity as measured by colony-forming and methylene-bluestaining assays. ATP efflux was strictly correlated with a rise in intracellular CAMP; therefore, the CAMP pathway is likely to be involved in triggering ATP efflux. These results demonstrate that yeast cells release ATP in a regulated manner.
\end{abstract}

Keywords: ATP efflux, cAMP mediated, ionophores and yeast, Saccharomyces cerevisiae

\section{INTRODUCTION}

In most tissues and organs, extracellular adenine nucleotides have diverse physiological effects that are principally mediated by the P2 purinergic receptors (Dubyak \& El-Moatassim, 1993; Chen et al., 1995; Lewis et al., 1995). In some cases, such as the stimulation of platelet aggregation and the mediation of pain perception, the source of extracellular nucleotide is damaged tissue. In other cases, such as with adrenal chromaffin cells, ATP is released from secretory granules during their fusion to the plasma membrane. Thirdly, ATP appears to move directly across the plasma membrane via a channel or transporter, as demonstrated by the release of ATP from cardiac myocytes and red blood cells during hypoxia (Forrester, 1990), and from smooth muscle cells upon stimulation with catecholamines (Sedaa et al., 1989).

The mechanism of release of ATP from animal cells through the plasma membrane is not known. ATP efflux

\footnotetext{
Abbreviations: $A B C, A T P$ binding cassette; $C C C P$, carbonyl cyanide $m$ chlorophenylhydrazone; CFTR, cystic fibrosis transmembrane conductance regulator; FCCP, carbonyl cyanide $\rho$-(trifluoromethoxy)phenylhydrazone: 4-NQO, 4-nitroquinoline- $N$-oxide; Pgp, P-glycoprotein.
}

has been correlated with the expression in the plasma membrane of a member of the ATP-binding cassette (ABC) superfamily of proteins, the multidrug resistance efflux pump P-glycoprotein (Pgp), in cultured mammalian cells (Abraham et al., 1993). The ABC protein cystic fibrosis transmembrane conductance regulator (CFTR) was shown to act as a dual ATP and $\mathrm{Cl}^{-}$ channel in the plasma membrane of mammalian cells (Reisin et al., 1994). Furthermore, it has been shown that one role of CFTR is to provide extracellular ATP which stimulates outwardly rectifying chloride channels in airway epithelia (Schwiebert et al., 1995). However, subsequent work has not supported the idea that the CFTR is a conduit for ATP (Reddy et al., 1996; Li et al., 1996; Grygorczyk et al., 1996). In any event, it seems that $A B C$ proteins, which have a broad expression pattern and are present in a wide variety of organisms, including yeast, (Blight \& Holland, 1990; Doige \& Ames, 1993; Gotessman \& Pastan, 1993; Balzi et al., 1994; Bissinger \& Kuchler, 1994; Dean et al., 1994; Servos et al., 1993) may play a role in ATP efflux (Guidotti, 1996).

It is not known whether adenine nucleotides are also released into the extracellular environment by unicellular organisms, except for cAMP which is released in large amounts from bacteria, yeasts and slime moulds 
(Firtel et al., 1989; Matin \& Matin, 1982; Saier et al., 1975; Smith et al., 1990). During sporulation of Saccharomyces cerevisiae, however, extracellular nucleotides are present and appear to act as intercellular signals, and may be taken up by the cells (Jakubowski $\&$ (roldman, 1988).

In view of the ability of all cells to release cAMP (Brunton \& Heasley, 1988), we asked whether ATP release is also a feature of unicellular organisms. In this paper we describe experiments which demonstrated ATP efflux from $S$. cerevisiae. This efflux required glucose and was stimulated by proton ionophores and an inhibitor of the plasma membrane proton pump. This stimulation of ATP efflux is likely to be mediated by the CAMP pathway because when the $\mathrm{pH}$ was raised to prevent the nigericin-induced cAMP response, nigericin did not stimulate ATP efflux. The basal and stimulated ATP efflux activities were not caused by cell lysis or non-specific permeability, and were observed in washed cells suspended in defined buffer and in cells growing in liquid culture. It thus appears that $S$. cerevisiae contains the capacity to increase ATP efflux when the intracellular cAMP concentration rises. The data suggest that yeast cells provide a good model system for studying ATP efflux; furthermore, the results suggest the possibility that extracellular ATP, ADP, AMP or adenosine play a role in yeast physiology, possibly as intercellular signals.

\section{METHODS}

Saccharomyces cerevisiae strains. Yeast strains YMR4, YMR400 and YHH33 were obtained from Albert Hinnen (Ciba-Geigy Ltd, Basel, Switzerland). The genotypes are as follows. YMR 4: MAT a his3-11,15 leu2-3,112 ura3 55 can Res

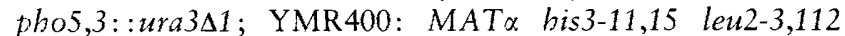
ura3 35 can Res pho5,3::URA3 PHO5wt; YHH33: MATa his3-11,15 leu2-3,112 pho5. Yeast cells were grown and maintained on synthetic complete $(2 \%$ dextrose) medium (Sherman et al., 1986). The wild-type yeast described in the text is strain CTY182 obtained from Vytas Bankaitis (University of Alabama, USA).

Materials. All drugs were purchased from Sigma. The HPLC columns used were Vydac nucleotide analysis column and a Hydropore sax column. The cAMP assay system was purchased from Amersham.

Extracellular nucleotide sample preparation. Cells were grown to exponential phase $\left(\mathrm{OD}_{650}\right.$ of $\left.2 \cdot 0\right)$ on glucosecontaining medium, washed with $20 \mathrm{mM}$ Tris/citrate, $\mathrm{pH} 5 \cdot 5$, resuspended in the appropriate cold incubation buffer at a cell density of $5.2 \times 10^{8}$ cells ml $^{-1}\left(O D_{650}\right.$ of 1 corresponded to $1.6 \times 10^{7}$ cells $\left.\mathrm{ml}^{-1}\right)$, and moved to room temperature $\left(23-28^{\circ} \mathrm{C}\right)$ at time zero. The samples were incubated at room temperature for the appropriate time period, after which each sample was filtered through a $0.2 \mu \mathrm{m}$ syringe-tip filter. The filtrate was then stored at $-70^{\circ} \mathrm{C}$ until HPLC analysis was performed. For the experiment shown in Fig. 6, extracellular nucleotides were isolated by filtering samples of the cell culture; the filtrate was then subjected to HPLC analysis.

Intracellular nucleotide sample preparation. Cell suspensions were prepared and incubated as described for the extracellular ATP samples. Intracellular nucleotides were then isolated as described by Pogolotti \& Santi (1982). Briefly, at the end of each incubation, the cells were pelleted, resuspended in $0.5 \mathrm{ml}$ $0.6 \mathrm{M}$ trichloroacetic acid and incubated at $0{ }^{\circ} \mathrm{C}$ for at least $10 \mathrm{~min}$. The precipitate was removed by centrifugation, and the supernatant was extracted with freon/trioctylamine (TOA). The samples were stored at $-70^{\circ} \mathrm{C}$ until HPLC analysis was performed.

HPLC analysis. One hundred microlitres of each sample was subjected to HPLC to separate the nucleotides in the sample as described by Pogolotti \& Santi (1982) and the ATP and ADP were quantified. The procedure for separating nucleotides was: solvent $\mathrm{A}, 0.045 \mathrm{M} \mathrm{NH}_{4} \mathrm{COOH}, \mathrm{pH} 4.6$, in $\mathrm{H}_{3} \mathrm{PO}_{4}$; solvent $\mathrm{B}, 0.275 \mathrm{M} \mathrm{NaH}_{2} \mathrm{PO}_{4}, \mathrm{pH} 2 \cdot 7$, in $\mathrm{HCOOH}$; gradient,

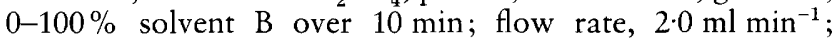
detection, $254 \mathrm{~nm}$. Data were quantified either by hand or by using Beckman System Gold software.

CAMP assays. Samples were prepared as described in 'Intracellular nucleotide sample preparation'. cAMP assays, using the competitive binding of cAMP and $\left[{ }^{3} \mathrm{H}\right] \mathrm{cAMP}$ to binding protein, were conducted using the 'Cyclic AMP $\left[{ }^{3} \mathrm{H}\right]$ Assay System' (Amersham).

Viability assays. Cells were grown to exponential phase, then prepared and incubated in $20 \mathrm{mM}$ Tris/citrate pH 5.5, with the addition of nigericin and/or glucose as indicated in Fig. 4,

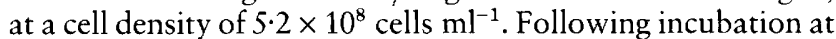
$23-28^{\circ} \mathrm{C}$ for the times indicated in Fig. 4, samples of the cells were diluted in water, 200 cells were spread onto each YPD plate and the plates were incubated at $30^{\circ} \mathrm{C}$ for $2 \mathrm{~d}$. Colonies were then counted to determine the number of viable cells on each plate.

Methylene blue assay. Cells were isolated and incubated as in the previous experiments except that the incubation buffers also contained $0.01 \%(\mathrm{w} / \mathrm{v})$ methylene blue. At the times indicated in Fig. 5, the cells were diluted into $0.01 \%$ methylene blue to a cell density suitable for counting in a haemocytometer; total and blue cells were counted.

\section{RESULTS}

\section{ATP efflux}

To avoid hydrolysis of extracytoplasmic ATP by periplasmic acid phosphatases (Nosaka, 1990; Vogel \& Hinnen, 1990) we used the Saccharomyces cerevisiae strain YMR4, which is deficient in both the PHO5 and PHO3 genes. Preliminary experiments verified that YMR4 cells do not contain measurable extracellular ATPase activity while cells containing either acid phosphatase gene were able to hydrolyse extracellular ATP (unpublished observations).

Fig. 1 shows the time course of the efflux of ATP and ADP (a) and the intracellular amounts of ATP and ADP (b) in the presence and absence of glucose. It is clear that there is a glucose-dependent efflux of ATP from these cells. After 50 min the amount of extracellular ATP in the presence of glucose (Fig. 1a) is approximately six times the amount seen in the absence of glucose (Fig. 1a).

Having established that yeast cells release ATP, it was of interest to determine whether compounds known to be toxic to yeast would have any effect on this phenomenon. The rationale for this approach is that the Pgp, which is responsible for the extrusion of some toxins 

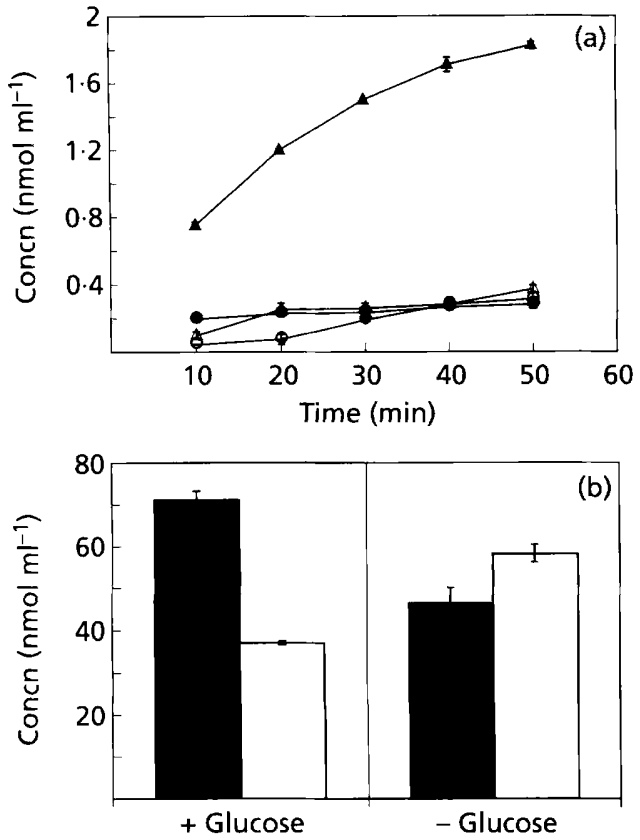

Fig. 1. Time course of ATP efflux. Samples were prepared as described in Methods. All incubation buffers were $20 \mathrm{mM}$ Tris/citrate, $\mathrm{pH} 5 \cdot 5$, with or without $2 \%(\mathrm{w} / \mathrm{v})$ glucose. (a) $\triangle, \boldsymbol{\Delta}$, with glucose; $0, \boldsymbol{\theta}$, without glucose; $\boldsymbol{\Delta}, \boldsymbol{0}$, extracellular ATP; $\triangle, O$, extracellular ADP. (b) Intracellular ATP (filled columns) and ADP (open columns) after $50 \mathrm{~min}$ incubation. Data represent means \pm variances, $n=2$.

from mammalian cells, seems to mediate the efflux of ATP (Abraham et al., 1993). Nigericin, a $\mathrm{H}^{+} / \mathrm{K}^{+}$ ionophore, was chosen because of its toxicity to yeast (Kovac et al., 1982) and because previous data indicated an interaction between nigericin and a mammalian Pgp when expressed in yeast (Boyum \& Guidotti, 1997). Fig. 2(a) shows that nigericin dramatically stimulates the efflux of ATP (note the change in scale from Fig. 1). This efflux also requires the presence of glucose (Fig. 2a). These data demonstrate that the release of ATP from yeast is stimulated by nigericin, and that the stimulated efflux also requires glucose.

To further characterize ATP efflux, additional experiments were conducted with several classes of compounds (Table 1). These included the $\mathrm{Na}^{+} / \mathrm{H}^{+}$exchanger monensin and the proton ionophores CCCP and FCCP, which dramatically stimulated ATP efflux; the plasma membrane proton pump inhibitor diethylstilbestrol (Serrano, 1988), which also stimulated ATP efflux; compounds which appear to interact with $\mathrm{ABC}$ transporters in yeast (Bissinger \& Kuchler, 1994; Kuchler \& Thorner, 1992; Servos et al., 1993), valinomycin, 4nitroquinoline- $\mathrm{N}$-oxide (4-NQO) and cycloheximide, which had no effect on ATP efflux; and an inhibitor of CFTR-mediated ATP efflux in mammalian cells, glybenclamide (Schwiebert et al., 1995), which had no effect on either the basal or the nigericin-stimulated efflux shown here. Fig. 3 shows that diethylstilbestrol and nigericin both affect ATP efflux in a concentration-
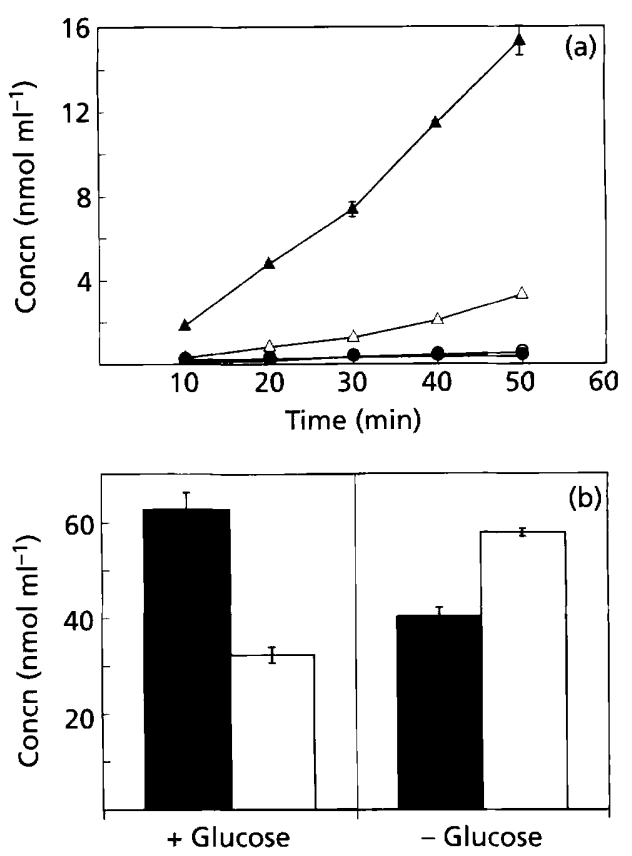

Fig. 2. Time course of nigericin-stimulated ATP efflux. Samples were prepared as described in Methods. All incubation buffers were $20 \mathrm{mM}$ Tris/citrate, $\mathrm{pH} 5.5,0.25 \%(\mathrm{v} / \mathrm{v})$ ethanol, $25 \mu \mathrm{g}$ nigericin $\mathrm{ml}^{-1}$, with or without $2 \%$ glucose. (a) $\triangle, \boldsymbol{\Delta}$, with glucose; $O, 0$, without glucose; $\boldsymbol{A}$, extracellular ATP; $\triangle, O$, extracellular ADP. (b) Intracellular ATP (filled columns) and ADP (open columns) after $50 \mathrm{~min}$ incubation. Data represent means \pm variances, $n=2$.

\section{Table 1. Effects of various compounds on ATP efflux}

Samples were prepared as described in Methods with $30 \mathrm{~min}$ incubation times. One hundred per cent was typically $2.7 \mathrm{nmol} \mathrm{ml}{ }^{-1}$. Data represent means $\pm \mathrm{sD}$.

\begin{tabular}{|lcc|}
\hline & $\begin{array}{c}\text { Percentage } \\
\text { of control }\end{array}$ & $\begin{array}{c}\text { No. of } \\
\text { assays }\end{array}$ \\
\hline Nigericin $(0 \cdot 034 \mathrm{mM})$ & $411 \cdot 1 \pm 7 \cdot 1$ & 3 \\
Monensin $(0 \cdot 034 \mathrm{mM})$ & $276 \cdot 0 \pm 9 \cdot 4$ & 3 \\
CCCP $(0 \cdot 034 \mathrm{mM})$ & $337 \cdot 9 \pm 1 \cdot 5$ & 3 \\
FCCP $(0 \cdot 034 \mathrm{mM})$ & $293 \cdot 3 \pm 21 \cdot 0$ & 3 \\
Diethylstilbestrol $(1.9 \mathrm{mM})$ & $134 \cdot 5 \pm 2 \cdot 9$ & 2 \\
Cycloheximide $(0 \cdot 034 \mathrm{mM})$ & $97 \cdot 1 \pm 2 \cdot 0$ & 2 \\
4-NQO $(0 \cdot 034 \mathrm{mM})$ & $98 \cdot 5 \pm 4 \cdot 0$ & 2 \\
Valinomycin $(0 \cdot 034 \mathrm{mM})$ & $100 \cdot 7 \pm 3 \cdot 3$ & 2 \\
Glybenclamide $(0 \cdot 1 \mathrm{mM})$ & $100 \cdot 4 \pm 2 \cdot 7$ & 3 \\
Glybenclamide $(0 \cdot 1 \mathrm{mM})$ & $429 \cdot 7 \pm 24 \cdot 3$ & 3 \\
+ nigericin $(0 \cdot 034 \mathrm{mM})$ & & \\
\hline
\end{tabular}

dependent and saturable manner. At $25 \mu \mathrm{g} \mathrm{ml}^{-1}$, the concentration used in these studies, the effect of nigericin was at a maximum, and the effect of diethylstilbestrol was also at a maximum at $1.9 \mathrm{mM}$. In all cases, ATP efflux required glucose. 

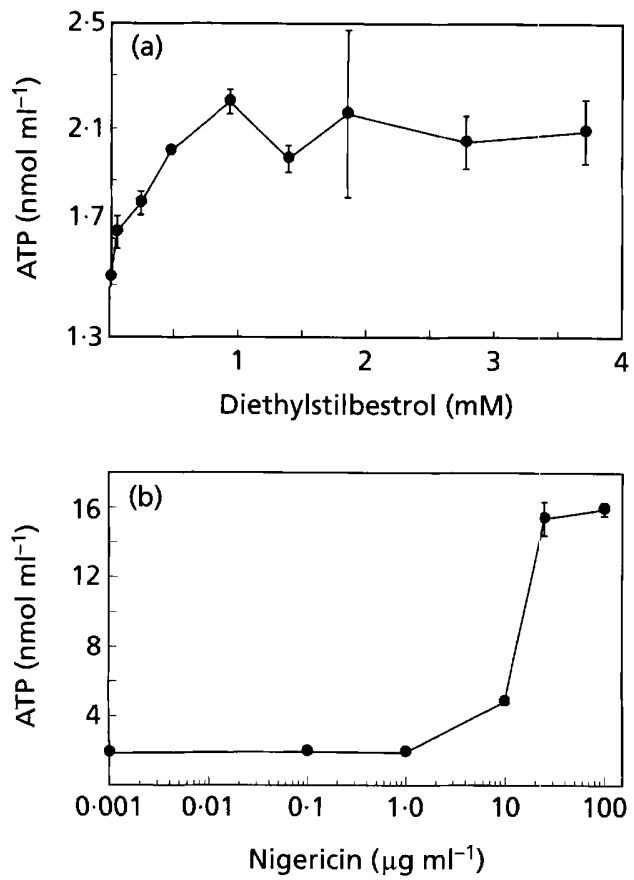

Fig. 3. Dose dependence of diethylstilbestrol and nigericinstimulated ATP efflux. Extracellular ATP samples were prepared as described in Methods. The incubation time for all samples was $50 \mathrm{~min}$. The incubation buffer was $20 \mathrm{mM}$ Tris/citrate, pH 5.5, $2 \%$ glucose. (a) Incubation buffers also contained $4 \%$ (v/v) DMSO and diethylstilbestrol at the indicated -oncentrations. Data were obtained from two to four ndependent experiments. (b) Incubation buffers also contained $0.25 \%$ ethanol and nigericin at the concentrations indicated. Data were obtained from two independent experiments. Data represent means $+S D$.

The ATP efflux seen in acid phosphatase mutant cells is not specific to these cells. When wild-type yeast cells were used in the experiments, extracellular ATP was observed, but the amounts were small due to hydrolysis and therefore difficult to measure. For instance, when the experiment was conducted at $\mathrm{pH} 5 \cdot 5$, the amount of extracellular ATP was undetectable by HPLC after a $30 \mathrm{~min}$ incubation unless nigericin and glucose were included, in which case the extracellular ATP concentration was $1.144 \mathrm{nmol} \mathrm{ml}^{-1}$. When the same experiment was conducted at $\mathrm{pH} 8.8$, which partially inactivates the periplasmic acid phosphatases (data not shown), extracellular ATP was not detected in the absence of glucose, but its concentration was $0.470 \mathrm{nmol} \mathrm{ml}{ }^{-1}$ in the presence of glucose and $1.857 \mathrm{nmol} \mathrm{ml}^{-1}$ in the presence of both nigericin and glucose. These results indicate that the release of ATP, and its stimulation by proton ionophores, is a general phenomenon in yeast, and not limited to cells lacking periplasmic acid phosphatases. Furthermore, since extracellular adenosine is not metabolized or taken up by yeast cells (Anderson \& Roth, 1976; Deeley, 1992), A TP release from wild-type yeast cells will lead to an accumulation of extracellular adenosine, which may

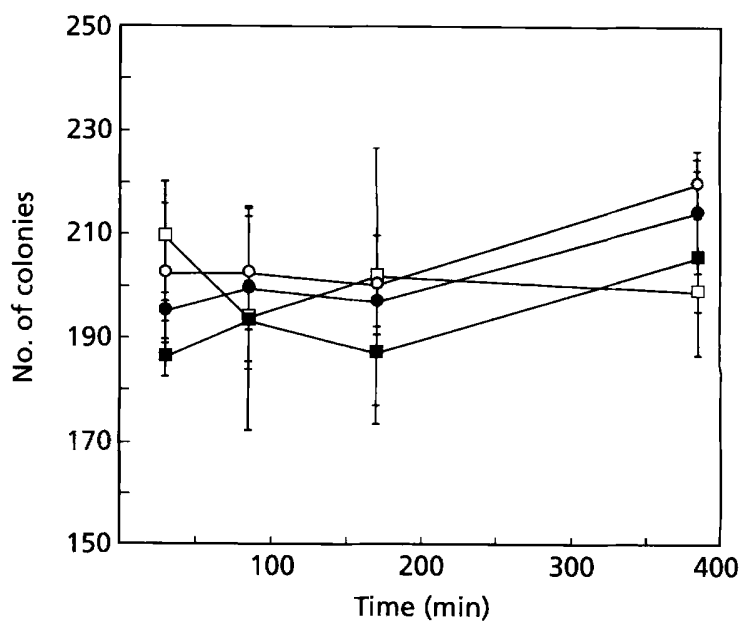

Fig. 4. ATP efflux assay conditions have no effect on the viability of the yeast cells during the time course of the assays. Cells were prepared and incubated as described in Methods. Presence $(\square, \square)$ and absence $(0,0)$ of $25 \mu \mathrm{g}$ nigericin $\mathrm{ml}^{-1}$. filled symbols indicate the presence of $2 \%$ glucose. Data represent means \pm SD of three experiments.

then play a physiological role in addition to any role played by ATP.

If the effect of compounds which stimulate ATP efflux was to permeabilize the plasma membrane non-specifically, the relative concentrations of extracellular ATP and ADP would be a direct reflection of their intracellular concentrations. This would cause the efflux of ATP to appear to be glucose-dependent because the intracellular concentration of ATP is higher in the presence of glucose than in its absence (Figs 1 and 2). However, the extracellular concentration of ADP would be expected to be higher in the absence of glucose because its intracellular concentration was higher in the absence of glucose than in its presence. This is not the case, however, because extracellular ADP was at very low levels when glucose was absent, even though the intracellular level of ADP increased under these conditions. This point is illustrated in Figs 1 and 2: panels (a) show the level of extracellular ADP, and panels (b) show the intracellular levels of ATP and ADP at the end of the 50 min incubation. In these experiments, the nucleotides quantified in panels (a) and (b) represent the amounts obtained from the same number of cells. In all cases, the efflux of ADP was higher in the presence of glucose than in its absence, even though the intracellular level of ADP was lower in the presence of glucose. Therefore, the observed increases in extracellular nucleotide are not a result of non-specific permeability.

\section{Cell viability}

The previous data concerning the glucose-dependence of ATP and ADP efflux suggest that nucleotide efflux is not due to lysis or non-specific permeability. In fact, incubation of cells with nigericin for up to $6 \mathrm{~h}$ did not 


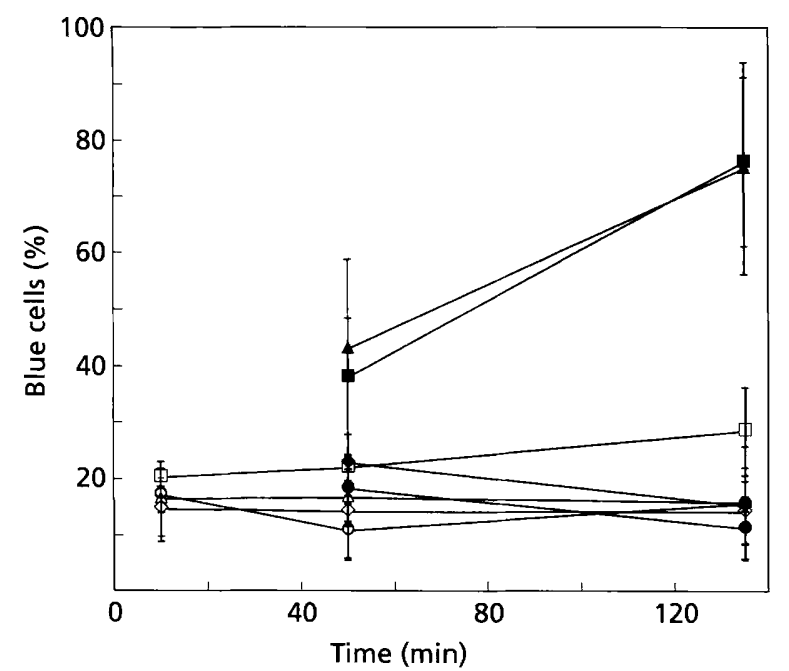

Fig. 5. ATP efflux assay conditions have no effect on plasma membrane integrity as observed using the methylene blue assay. Cells were prepared and incubated as described in Methods. $\square, \triangle$. Presence of $25 \mu$ g nigericin $\mathrm{ml}^{-1} ; 0, \diamond$, absence of nigericin. $\mathbf{D}, \mathbf{\Delta}$, Presence of $1 \mathrm{mg}^{-1}$ nstatin $\mathrm{ml}^{-1}$; $\bullet$, absence of nystatin. Squares and circles indicate the presence of $2 \%$ glucose; triangles and diamonds indicate the absence of glucose. Data represent means \pm SD for three experiments.

result in a decrease in the number of viable cells, as measured by a colony-forming assay, indicating that there was no cell lysis (Fig. 4). If the release of $25 \%$ of the intracellular ATP in $50 \mathrm{~min}$ (as seen in Fig. 2) were due to cell lysis, there should be an obvious loss of viability in the first hour in the presence of nigericin and glucose. However, there was no apparent loss of viability for more than $6 \mathrm{~h}$ following the addition of $25 \mu \mathrm{g}$ nigericin $\mathrm{ml}^{-1}$.

Fig. 5 shows that nigericin does not cause an increase in non-specific permeability as measured by the methylene blue assay. This assay is based on the observation that viable yeast cells exclude the dye from the cytoplasm and remain colourless while non-viable or permeable yeast cells stain blue (Hieda et al., 1984). This experiment provides a real time complement to the experiment shown in Fig. 4 because it demonstrates that nigericin does not cause a temporary and glucosedependent increase in plasma membrane permeability. As a positive control for this assay, nystatin was shown to cause a dramatic increase in the percentage of blue cells that was independent of the presence of glucose. This is expected because nystatin is known to induce non-specific permeability of the plasma membrane (Ikehara et al., 1986).

\section{Role of CAMP}

The addition of glucose to yeast cells is known to induce an increase in intracellular cAMP (Thevelein et al., $1987 b$ ). Also, exposure of yeast to proton ionophores and diethylstilbestrol raises intracellular cAMP; this rise, unlike that caused by glucose, is due to intracellular acidification and does not occur at alkaline $\mathrm{pH}$ (Thevelein et al., 1987a). These data raise the possibility that ATP efflux from yeast is triggered by a rise in intracellular cAMP. The data shown in Table 2 support

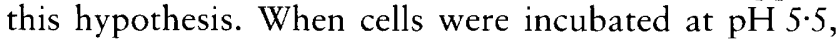
nigericin caused an initial rise in intracellular cAMP, as measured $7 \mathrm{~min}$ after the start of the experiment. In contrast, when cells were incubated at alkaline $\mathrm{pH}$, a condition under which nigericin cannot induce intracellular acidification, the cAMP level did not rise above the level caused by glucose alone. When extracellular ATP was measured under the same conditions and at the same time point of $7 \mathrm{~min}$, it was seen that nigericin induced ATP efflux to a much greater extent at $\mathrm{pH} 5.5$ than at $\mathrm{pH} 8 \cdot 8$. The omission of glucose led to a lower level of cAMP in all cases and prevented appreciable ATP efflux in this short experiment (data not shown). The measurements of cAMP and ATP were made after a short time $(7 \mathrm{~min})$ because at later time points, cellular metabolism caused acidification of the medium which then allowed a nigericin-stimulated increase in intracellular cAMP and ATP efflux as was shown for the

\section{Table 2. Role of CAMP in ATP efflux}

Cells were prepared and incubated as described in Methods. All incubations included $2 \%$ glucose. pH $5 \cdot 5$ indicates that the incubation buffer was $20 \mathrm{mM}$ Tris/citrate, $\mathrm{pH} 5 \cdot 5 ; \mathrm{pH} 8.8$ indicates that the incubation buffer was $20 \mathrm{mM}$ Tris, $\mathrm{pH} 8.8$. Data were recorded after $7 \mathrm{~min} ; n=2$ for cAMP, $n=1$ for ATP. Data are expressed as a percentage of the amount seen in the absence of nigericin (cAMP, $27 \mathrm{pmol} \mathrm{m}^{-1}$ at $\mathrm{pH} 5.5$ and $43 \mathrm{pmol} \mathrm{ml}^{-1}$ at $\mathrm{pH} 8.8 ; \mathrm{ATP}, 33 \mathrm{pmol} \mathrm{m}^{-1}$ at pH 5.5 and $27 \mathrm{pmol} \mathrm{ml}^{-1}$ at $\mathrm{pH}^{8.8}$ ). + Nigericin indicates the presence of $25 \mu \mathrm{g}$ nigericin $\mathrm{ml}^{-1}$.

\begin{tabular}{|c|c|c|c|c|}
\hline & \multicolumn{4}{|c|}{ ATP efflux $(\%)$} \\
\hline & \multicolumn{2}{|c|}{$\mathrm{pH} 5 \cdot 5$} & \multicolumn{2}{|c|}{ pH $8 \cdot 8$} \\
\hline & + Nigericin & - Nigericin & + Nigericin & - Nigericin \\
\hline $\begin{array}{l}\text { Intracellular cAMP } \\
\text { Extracellular ATP }\end{array}$ & $\begin{array}{c}181 \cdot 2 \pm 12 \cdot 4 \\
384 \cdot 8\end{array}$ & $\begin{array}{c}100 \cdot 0 \pm 11 \cdot 3 \\
100 \cdot 0\end{array}$ & $\begin{array}{c}108 \cdot 8 \pm 2 \cdot 1 \\
163 \cdot 0\end{array}$ & $\begin{array}{c}100 \cdot 0 \pm 20 \cdot 3 \\
100 \cdot 0\end{array}$ \\
\hline
\end{tabular}



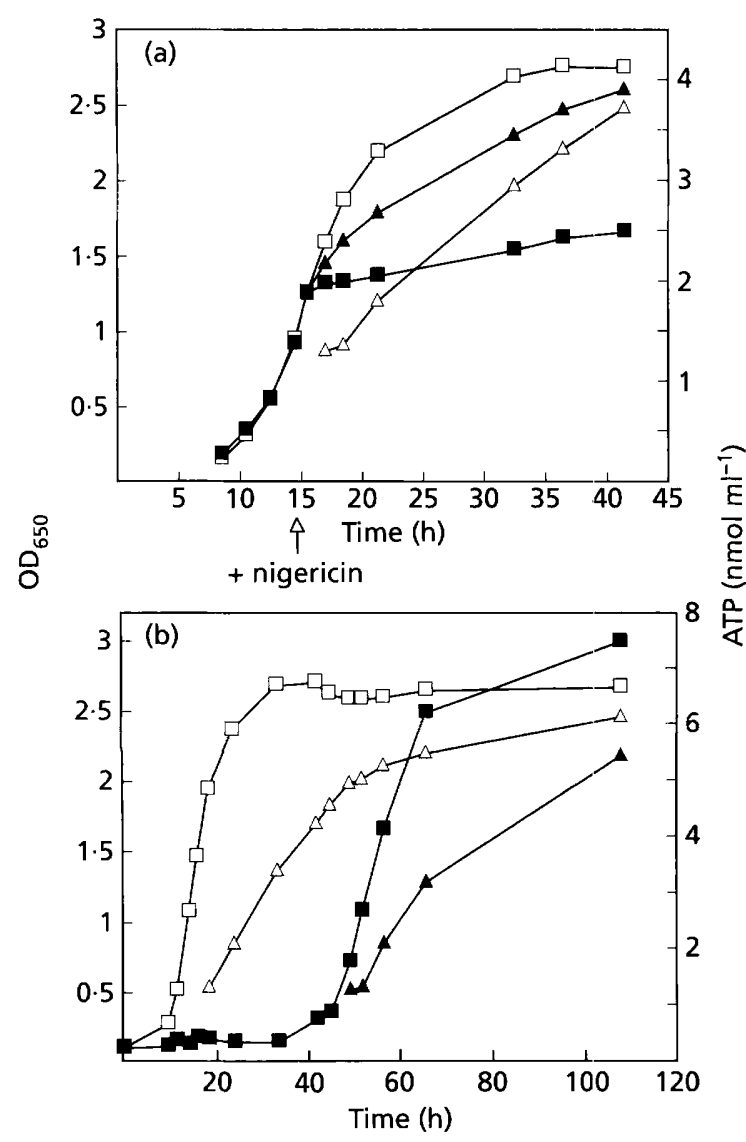

Fig. 6. ATP efflux from growing cells. One hundred microlitres of a saturated culture of YMR4 cells was used to inoculate two batches of fresh synthetic complete dextrose medium. Growth of the cultures and levels of extracellular ATP were then monitored as described in Methods. Nigericin was added (to $25 \mu \mathrm{g} \mathrm{ml}^{-1}$ ) after $14.5 \mathrm{~h}$ (arrow in panel $\mathrm{A}$ ). $\square, \square, O_{650} ; \triangle, \Delta$, extracellular ATP in the culture; $\boldsymbol{\square}, \mathbf{\Delta}$, nigericin-containing culture: $\square, \triangle$, control. (a) Growth and extracellular ATP in the cultures showing the acute effect of nigericin. (b) Growth and extracellular ATP in the cultures showing the chronic effect of nigericin. Only detectable levels of extracellular ATP are reported; at earlier time points, the level of ATP was below the limit of detection of the column used for this experiment.

wild-type cells described earlier. These data show that at alkaline $\mathrm{pH}$, while glucose affects both intracellular cAMP and extracellular ATP, nigericin has no effect on either intracellular cAMP or extracellular ATP because it cannot acidify the cell under these conditions. This result supports the idea that cAMP is important in regulating ATP efflux.

\section{ATP efflux during growth}

The previous experiments demonstrate that yeast cells, when harvested and suspended in a defined buffer, release ATP under conditions in which the intracellular cAMP concentration rises. To address the physiological significance of this ATP efflux, it was necessary to determine whether ATP is also released from cells in actively growing cultures. Therefore, extracellular ATP was monitored during the growth of yeast cells. Fig. 6(a) shows that the growth of yeast was dramatically slowed by the addition of nigericin compared to growth in medium without nigericin. Fig. 6(a) also shows that ATP accumulated in both cultures and accumulated more rapidly in the nigericin-containing culture, even though this culture was growing much more slowly and thus contained a lower cell density at the later time points. Fig. 6(b) shows that cells eventually grew in a culture containing nigericin and that these cells released ATP to an extent similar to cells grown in medium without nigericin. The eventual growth of the cells in the presence of nigericin is not due to a simple removal of nigericin from the medium. These cells will grow without delay after dilution into fresh nigericincontaining medium (data not shown). The fact that acute exposure of the growing cells to nigericin led to increased ATP efflux (Fig. 6a) is consistent with what one would expect for a process mediated by a transient rise in intracellular cAMP. Apparently, ATP efflux and its stimulation by nigericin take place during normal growth, as well as under unusual experimental conditions. This suggests that ATP efflux is a component of yeast physiology.

\section{DISCUSSION}

It is clear from the present work that $S$. cerevisiae cells contain a glucose-dependent ATP release mechanism that is stimulated by proton ionophores and diethylstilbestrol, an inhibitor of the plasma membrane proton pump. The idea that ATP efflux is triggered by a rise in intracellular cAMP is supported by the following observations: glucose is absolutely required (Figs 1 and 2) and glucose is known to cause a rise in cAMP (Thevelein et al., 1987b); proton ionophores and diethylstilbestrol, which cause intracellular acidification and thereby raise the cAMP concentration (Thevelein $e t$ al., 1987a; Table 2), stimulate ATP efflux (Fig. 2 and Table 1); valinomycin, which can affect membrane potential but not intracellular $\mathrm{pH}$ or cAMP (Thevelein et al., 1987a), has no effect on ATP efflux (Table 1); cycloheximide, 4-NQO, and glybenclamide, which are unlikely to affect intracellular $\mathrm{pH}$, have no effect on ATP efflux (Table 1); and nigericin does not stimulate ATP efflux under alkaline conditions that prevent cellular acidification and the subsequent rise in intracellular cAMP (Table 2). ATP efflux is seen in washed cells suspended in a defined buffer and in cells growing in liquid culture. The fact that cell lysis or non-specific permeability are not responsible for the increase in extracellular ATP is supported by three findings: the glucose dependence of ADP efflux (Figs 1 and 2), the maintenance of cell viability during nigericin exposure (Fig. 4) and the demonstration of plasma membrane integrity by the methylene blue assay (Fig. 5).

The glucose dependency of the protonophore effect on ATP efflux may be due to the fact that the cells are grown on glucose and are therefore glucose-repressed. It is known that glucose-repressed cells are unable to synthesize CAMP in the absence of glucose when exposed 
to protonophores (Arguelles et al., 1990). The absence of a cAMP signal under these conditions would therefore result in no protonophore stimulation of ATP efflux. This is further indication of the role of cAMP in ATP efflux.

There is an apparent, but incomplete specificity of the ATP efflux mechanism. Other nucleotides, such as GTP, were sometimes detected and appeared to be released at very low levels along with ATP (data not shown). The low level of release of other nucleotide triphosphates may be a result of specificity for ATP, the very low intracellular concentration of these molecules in relation to ATP, or both. Since it is known that cAMP is released to the extracellular medium (Smith et al., 1990) and that the conditions that stimulate ATP efflux, the addition of glucose and proton ionophores, also cause a rise in intracellular CAMP, it is reasonable to speculate that ATP and cAMP may be released from the cell by the same carrier.

The increased appearance of extracellular ATP, caused by proton ionophores and diethylstilbestrol, is likely due to a stimulation of efflux rather than to interference with an ATP uptake mechanism because yeast cells are known not to have adenine nucleotide uptake activity (Anderson \& Roth, 1976; Deeley, 1992). It has been shown, however, that adenine-requiring strains can satisfy the adenine requirement with adenosine if it gains access to the cytoplasm by detergent solubilization of the plasma membrane or by mutation, supporting the view that yeast cells do not normally contain an uptake mechanism for adenine nucleotides (Anderson \& Roth, 1976; Deeley, 1992). One exception to this generalization is the finding that sporulating yeast cells apparently utilize extracellular nucleotides and these compounds are required for adenine auxotrophs to undergo sporulation (Jakubowski \& Goldman, 1988). The mechanism of this import into sporulating yeast cells is not known; however, both efflux and uptake may occur via non-specific permeability due to a lack of structural integrity of the plasma membrane. In contrast, the ATP efflux reported here is not a result of nonspecific permeability of the plasma membrane.

Several, not necessarily exclusive, possibilities for the purpose of ATP efflux from yeast exist. One, suggested by the stimulation by various compounds, is that ATP efflux is involved in or is a consequence of a cellular detoxification mechanism, similar to one theory of Pgp activity (Abraham et al., 1993). A second possibility is that extracellular ATP is needed by an enzyme such as an ectokinase for some unknown biochemical function. A third possibility is that ATP is released as a means of regulating the intracellular ATP concentration or the local concentration of ATP at the plasma membrane. A very intriguing possibility is that extracellular ATP, or one of the products of its hydrolysis by the periplasmic acid phosphatases, ADP, AMP or adenosine, could perform an intercellular signalling function in yeast.

In summary, these studies demonstrate that yeast cells release ATP to the extracellular fluid, this release requires glucose and is stimulated by compounds that cause a rise in intracellular cAMP. This is the first step in determining whether the release of ATP from the cytoplasm and/or the presence of ATP extracellularly have a role in yeast physiology, possibly in intercellular signalling. Furthermore, the fact that yeast cells release and hydrolyse extracellular ATP opens additional questions concerning the role of the products of its hydrolysis, ADP, AMP and adenosine, as extracellular components of yeast physiology.

\section{ACKNOWLEDGEMENTS}

We thank Dr Ernest Peralta for critical reading of the manuscript and helpful suggestions and Albert Hinnen for the acid phosphatase mutant $S$. cerevisiae strains. This work was supported by NIH grant HL08893 to Guido Guidotti, and by a predoctoral fellowship from the Howard Hughes Medical Institute to Rodney Boyum.

\section{REFERENCES}

Abraham, E. H., Prat, A. G., Gerweck, L., Seneveratne, T., Arceci, R. J., Kramer, R., Guidotti, G. \& Cantiello, H. F. (1993). The multidrug resistance $(\mathrm{mdr} 1)$ gene product functions as an ATP channel. Proc Natl Acad Sci USA 90, 312-316.

Anderson, J. M. \& Roth, R. (1976). Adenosine utilization in cordycepin-sensitive mutants of Saccharomyces cerevisiae. J Bacteriol 128, 689-691.

Arguelles, J. C., Mbonyi, K., Van Aelst, L., Vanhalewyn, M., Jans, A. W. H. \& Thevelein, J. M. (1990). Absence of glucose-induced cyclic AMP signaling in the Saccharomyces cerevisiae mutants cat 1 and cat 3 which are deficient in derepression of glucoserepressible proteins. Arch Microbiol 154, 199-205.

Balzi, E., Wang, M., Leterme, S., Dyck, L. V. \& Goffeau, A. (1994). PDR5, a novel yeast multidrug resistance conferring transporter controlled by the transcription regulator PDR1. J Biol Chem 269, 2206-2214.

Bissinger, P. H. \& Kuchler, K. (1994). Molecular cloning and expression of the Saccharomyces cerevisiae STS1 gene product. J Biol Chem 269, 4180-4186.

Blight, M. A. \& Holland, I. B. (1990). Structure and function of haemolysin B, P-glycoprotein and other members of a novel family of membrane translocators. Mol Microbiol 4, 873-880.

Boyum, R. \& Guidotti, G. (1997). Effect of ATP binding cassette/multidrug resistance proteins on ATP efflux of Saccharomyces cerevisiae. Biochem Biophys Res Commun 230, 22-26.

Brunton, L. L. \& Heasley, L. E. (1988). cAMP export and its regulation by prostaglandin A1. Methods Enzymol 159, 83-92.

Chen, C.-C., Akopian, A. N., Sivilotti, L., Colquhoun, D., Burnstock, G. \& Ward, J. N. (1995). A P2X purinoceptor expressed by a subset of sensory neurons. Nature 377, 428-431.

Dean, M., Allikmets, R., Gerrard, B., Stewart, C., Kistler, A., Shafer, B., Michaelis, S. \& Strathern, J. (1994). Mapping and sequencing of two yeast genes belonging to the ATP-binding cassette superfamily. Yeast 10, 377-383.

Deeley, M. C. (1992). Adenine deaminase and adenine utilization in Saccharomyces cerevisiae. J Bacteriol 174, 3102-3110.

Doige, C. A. \& Ames, G. F. L. (1993). ATP-dependent transport systems in bacteria and humans: relevance to cystic fibrosis and multidrug resistance. Annu Rev Microbiol 47, 291-319. 
Dubyak, G. R. \& El-Moatassim, C. (1993). Signal transduction via $\mathrm{P}_{2}$-purinergic receptors for extracellular ATP and other nucleotides. Am J Physiol 265, C577-C606.

Firtel, R. A., van Haastert, P. J. M., Kimmel, A. R. \& Devreotes, P. N. (1989). G protein linked signal transduction pathways in development: dictyostelium as an experimental system. Cell $\mathbf{5 8}$, 2.35-239.

Forrester, T. (1990). Release of ATP from heart: presentation of a release model using human erythrocytes. Ann NY Acad Sci 603, $3.35-352$.

Gotessman, M. M. \& Pastan, I. (1993). Biochemistry of multidrug resistance mediated by the multidrug transporter. Annu Rev Biochem 62, 385-427.

Grygorczyk, R., Tabcharani, J. A. \& Hanrahan, J. W. (1996). CFTR channels expressed in $\mathrm{CHO}$ cells do not have detectable ATP conductance. J Membr Biol 151, 139-148.

Guidotti, G. (1996). ATP transport and ABC proteins. Chem Biol 3, 703-706.

Hieda, K., Kobayishi, K., Ito, A. \& Ito, T. (1984). Comparisons of the effects of vacuum-uv and far-uv synchrotron radiation on dry yeast cells of different uv sensitivities. Radiat Res 98, 74-81.

Ikehara, T., Yamaguchi, H., Hosokawa, K., Yonezu, T. \& Miyamoto, H. (1986). Effects of nystatin on intracellular contents and membrane transport of alkali cations, and cell volume in HeLa cells. J Membr Biol 90, 231-240.

Jakubowski, H. \& Goldman, E. (1988). Evidence for cooperation between cells during sporulation of the yeast Saccharomyces cerevisiae. Mol Cell Biol 8, 5166-5178.

Kovac, L., Bohmerova, E. \& Butko, P. (1982). Jonophores and intact cells. Biochim Biophys Acta 721, 341-348.

Kuchler, K. \& Thorner, J. (1992). Functional expression of human $m d r 1$ in the yeast Saccharomyces cerevisiae. Proc Natl Acad Sci USA 89, 2302-2306.

Lewis, C., Neidhart, S., Holy, C., North, R. A., Buell, G. \& Surprenant, A. (1995). Coexpression of $\mathrm{P} 2 \mathrm{X}_{2}$ and $\mathrm{P} 2 \mathrm{X}_{3}$ receptor subunits can account for ATP-gated currents in sensory neurons. Nature 377, 432-435.

Li, C., Ramjeesingh, M. \& Bear, C. E. (1996). Purified cystic fibrosis transmembrane conductance regulator (CFTR) does not function as an ATP channel. J Biol Chem 271, 11623-11626.

Matin, A. \& Matin, M. K. (1982). Cellular levels, excretion, and synthesis rates of cyclic AMP in E. coli grown in continuous culture. J Bacteriol 149, 801-807.

Nosaka, K. (1990). High affinity of acid phosphatase encoded by PHO3 gene in Saccharomyces cerevisiae for thiamin phosphates. Biochim Biophys Acta 1037, 147-154.

Pogolotti, A. L. \& Santi, D. V. (1982). High-pressure liquid chromatography-ultraviolet analysis of intracellular nucleotides. Anal Biochem 126, 335-345.
Reddy, M. M., Quinton, P. M., Haws, C., Wine, J. J., Grygorczyk, R., Tabcharani, J. A., Hanrahan, J. W., Gunderson, K. L. \& Kopito, R. R. (1996). Failure of the cystic fibrosis transmembrane conductance regulator to conduct ATP. Science 271, 1876-1879.

Reisin, I. L., Prat, A. G., Abraham, E. H., Amara, J. F., Gregory, R. J., Ausiello, D. A. \& Cantiello, H. F. (1994). The cystic fibrosis transmembrane conductance regulator is a dual ATP and chloride channel. J Biol Chem 269, 20584-20591.

Saier, M. H., Feucht, B. U. \& McCaman, M. T. (1975). Regulation of intracellular adenosine cyclic $3^{\prime}, 5^{\prime}$-monophosphate levels in $E$. coli and S. typhimurium. J Biol Chem 250, 7593-7601.

Schwiebert, E. M., Egan, M. E., Hwang, T. H., Fulmer, S. B., Allen, S. S., Cutting, G. R. \& Guggino, W. B. (1995). CFTR regulates outwardly rectifying chloride channels through an autocrine mechanism involving ATP. Cell 81, 1063-1073.

Sedaa, K. O., Bjur, R. A., Shinozuka, K. \& Westfall, D. P. (1989). Nerve and drug-induced release of adenine nucleosides and nucleotides from rabbit aorta. J Pharmacol Exp Ther 252, 1060-1067.

Serrano, R. (1988). $\mathrm{H}^{+}$-ATPase from plasma membranes of Saccharomyces cerevisiae and Avene sativa roots: purification and reconstitution. Methods Enzymol 157, 533-538.

Servos, J., Hasse, E. \& Brendel, M. (1993). Gene SNQ2 of Saccharomyces cerevisiae, which confers resistance to 4nitroquinoline- $\mathrm{N}$-oxide and other chemicals, encodes a $169 \mathrm{kDa}$ protein homologous to ATP-dependent permeases. Mol Gen Genet 236, 214-218.

Sherman, F., Fink, G. R. \& Hicks, J. A. (1986). Laboratory Manual for Yeast Genetics. Cold Spring Harbor, NY: Cold Spring Harbor Laboratory.

Smith, M. E., Dickinson, J. R. \& Wheals, A. E. (1990). Intracellular and extracellular levels of cyclic AMP during the cell cycle of Saccharomyces cerevisiae. Yeast 6, 53-60.

Thevelein, J. M., Beullens, M., Honshoven, F., Hoebeeck, G., Detremerie, K., Den Hollander, J. A. \& Jans, A. W. H. (1987a). Regulation of the cAMP level in the yeast Saccharomyces cerevisiae: intracellular $\mathrm{pH}$ and the effect of membrane depolarizing compounds. J Gen Microbiol 133, 2191-2196.

Thevelein, J. M., Beullens, M., Honshoven, F., Hoebeeck, G., Detremerie, K., Griewel, B., Den Hollander, J. A. \& Jans, A. W. H. (1987b). Regulation of the cAMP level in the yeast Saccharomyces cerevisiae: the glucose-induced cAMP signal is not mediated by a transient drop in the intracellular pH. J Gen Microbiol 133, 2197-2205.

Vogel, K. \& Hinnen, A. (1990). The yeast phosphatase system. Mol Microbiol 4, 2013-2017.

Received 19 November 1996; revised 3 February 1997; accepted 6 February 1997. 